ARTICLE

https://doi.org/10.1038/s41467-021-26962-w

\title{
Mechanochemical synthesis of magnesium-based carbon nucleophiles in air and their use in organic synthesis
}

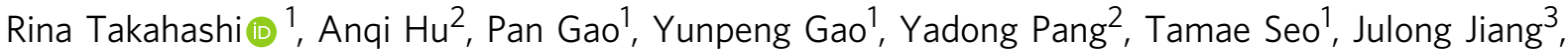

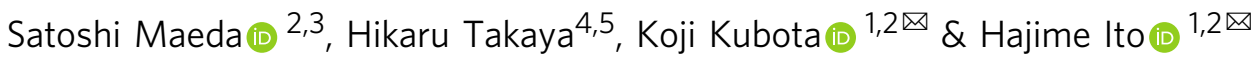

Since the discovery of Grignard reagents in 1900, the nucleophilic addition of magnesiumbased carbon nucleophiles to various electrophiles has become one of the most powerful, versatile, and well-established methods for the formation of carbon-carbon bonds in organic synthesis. Grignard reagents are typically prepared via reactions between organic halides and magnesium metal in a solvent. However, this method usually requires the use of dry organic solvents, long reaction times, strict control of the reaction temperature, and inert-gas-line techniques. Despite the utility of Grignard reagents, these requirements still represent major drawbacks from both an environmental and an economic perspective, and often cause reproducibility problems. Here, we report the general mechanochemical synthesis of magnesium-based carbon nucleophiles (Grignard reagents in paste form) in air using a ball milling technique. These nucleophiles can be used directly for one-pot nucleophilic addition reactions with various electrophiles and nickel-catalyzed cross-coupling reactions under solvent-free conditions.

\footnotetext{
${ }^{1}$ Division of Applied Chemistry, Graduate School of Engineering, Hokkaido University, Sapporo, Hokkaido 060-8628, Japan. ${ }^{2}$ Institute for Chemical Reaction Design and Discovery (WPI-ICReDD), Hokkaido University, Sapporo, Hokkaido 060-8628, Japan. ${ }^{3}$ Department of Chemistry, Faculty of Science, Hokkaido University, Sapporo, Hokkaido 060-8628, Japan. ${ }^{4}$ Institute for Chemical Research, Kyoto University, Gokasho, Uji, Kyoto 611-0011, Japan. ${ }^{5}$ Division of PhotoMolecular Science III/Advanced Molecular Science, Institute for Molecular Science, Myodaiji, Okazaki, Aichi 444-8585, Japan.

凶email: kbt@eng.hokudai.ac.jp; hajito@eng.hokudai.ac.jp
} 
T he discovery of what later became commonly known as the 'Grignard reagents' and their use as carbon nucleophiles were first reported in 1900 by Victor Grignard ${ }^{1}$. Since then, Grignard reagents have occupied an important place in organic chemistry, as they have been used to produce numerous synthetic intermediates and valuable functional molecules in the materials, pharmaceutical, food, polymer, and related chemical industries ${ }^{2-5}$. Thus, the development of efficient methods for their preparation has attracted considerable interest ${ }^{6-8}$. The direct insertion of magnesium metal into organic halides is one of the most established routes, as it is an atom-economical process with low toxicity (Fig. 1a) ${ }^{9}$. However, this method usually requires the use of dry organic solvents, long reaction times, strict control of the reaction temperature, and inert-gas-line techniques. Moreover, the surface of the magnesium metal may be covered with an unreactive oxide layer ${ }^{10}$, which requires a pre-activation process involving heating, ultrasound ${ }^{11}$, or microwave ${ }^{12}$ treatment, and/ or the addition of activating reagents ${ }^{13-15}$. Unfortunately, these requirements still represent major drawbacks from both an environmental and an economic perspective, and often cause reproducibility problems for unreactive organic halides.

In this context, the use of ball milling techniques ${ }^{16-24}$ for the solvent-free preparation of Grignard reagents via reactions between aryl halides and magnesium metal has been studied by several research groups (Fig. 1b). In 2001, Harrowfield and coworkers first attempted mechanochemical reactions of 1-chloroor 1-bromo-naphthalenes with magnesium metal in a glovebox ${ }^{25}$. Unfortunately, their subsequent one-pot nucleophilic addition to ketones resulted in complex product mixtures. As part of a search for dehalogenation reactions of harmful organic compounds, Birke and co-workers reported that the complete protonation of aryl chlorides could be achieved by milling them with magnesium and $n$-butyl amine in a glovebox ${ }^{26}$. More recently, Hanusa and co-workers reported the mechanochemical reactions of bromoor fluoroarenes with magnesium metal in a glovebox ${ }^{27}$. Subsequent addition of $\mathrm{FeCl}_{3}$ to the reaction mixture gave the corresponding homo-coupling products in moderate to low yield. However, one-pot mechanochemical reactions with carbonyl electrophiles did not provide the corresponding nucleophilic addition products. More recently, Yang, Dai, and co-workers also reported magnesium-mediated reductive radical homo-coupling reactions of polyhaloarenes ${ }^{28}$. Although these pioneering studies are highly remarkable, neither successful examples of the use of magnesium-based carbon nucleophiles prepared by ball milling for the formation of carbon-carbon bonds with various electrophiles ${ }^{29}$, nor direct spectroscopic evidence for the formation of carbon-magnesium bonds under mechanochemical conditions have been reported so far.

Herein, we report that a mechanochemical approach using ball milling allows for a highly efficient, general, and robust method for the preparation of magnesium-based carbon nucleophiles in air and their application to various organic transformations under mechanochemical conditions (Fig. 1c). The key to the success of this protocol is the addition of small amounts of tetrahydrofuran (THF) or cyclopentyl methyl ether (CPME), which facilitates the formation of organomagnesium nucleophiles and their addition to electrophiles. The carbon nucleophiles thus formed can be used for various transformations including carbonyl addition, carbon-silicon bond formation, nickel-catalyzed Kumada-Tamao-Korriu cross-coupling reactions, and metal-catalyzed selective addition reactions to conjugated enones under mechanochemical conditions. Notably, the developed protocol does not require the use of inert gas or dry organic solvents, allowing the entire procedure to be conducted in air without necessitating any special precautions or synthetic techniques. We also succeeded in the preparation of an organomagnesium reagent from a poorly soluble aryl halide, and it should be noted here that this reagent cannot be synthesized via conventional solution-based protocols. Near edge, X-ray absorption fine structure (NEXAFS) spectroscopy is used to analyze the generation of the magnesium-based carbon nucleophiles under mechanochemical conditions. The present study thus provides a new platform centered on magnesium-based carbon nucleophiles, which has the potential to update modern organic synthesis with a more cost-effective and environmental-friendly procedure for Grignard reactions.

\section{Results}

Mechanochemical synthesis of magnesium-based carbon nucleophiles in air. We first attempted the synthesis of organomagnesium species from bromobenzene [1a, 1.5 equiv for benzaldehyde (2a)] and magnesium turnings $[1.5$ equiv for benzaldehyde (2a)] and a subsequent nucleophilic addition to benzaldehyde (2a) using a Retch MM400 mixer mill $(5 \mathrm{~mL}$ stainless-steel milling jar with a $10 \mathrm{~mm}$-diameter stainless-steel ball) (Fig. 1d). After the ball milling of $\mathbf{1 a}$ and magnesium turnings for $60 \mathrm{~min}$, the jar was opened in air, and a gray oil was obtained (Fig. 1d, left photograph). Visible magnesium metal grains or powder were not observed in the mixture. Then, $2 \mathbf{a}$ was added to the jar and ball milling was continued for $60 \mathrm{~min}$. The desired nucleophilic addition product (3aa) was obtained, albeit in only $6 \%$ NMR yield. Next, we attempted to improve the reactivity by using liquid ethers as additives in order to facilitate the formation of the organomagnesium nucleophiles and their addition to the electrophiles. The use of 2.0 equivalents of tetrahydrofuran (THF) relative to the amount of magnesium afforded a muddy light-orange mixture (Fig. 1d, right photograph). Then, this mixture was ball-milled with $\mathbf{2 a}$, which dramatically improved the yield of 3aa to $94 \%$. We also tested other liquid ethers, such as diethyl ether $\left(\mathrm{Et}_{2} \mathrm{O}\right)$ and cyclopentyl methyl ether (CPME), but the resulting yields were lower than that obtained using THF. The use of liquid additives that do not contain an oxygen atom, such as hexane, did not improve the yield of 3aa. The protocol using THF as an additive was applied to the synthesis of magnesium-based carbon nucleophiles from iodobenzene $\left(\mathbf{1 a}^{\prime}\right)$ and chlorobenzene $\left(\mathbf{1} \mathbf{a}^{\prime \prime}\right)$, and the desired alcohol 3aa was obtained in good yields of 74 and $84 \%$, respectively (for details, see the Supplementary Material). Notably, the reaction of 1a and magnesium was also carried out on a gram scale in a $10 \mathrm{~mL}$ stainless-steel ball-milling jar with two $15 \mathrm{~mm}$-diameter stainless-steel balls to afford $\mathbf{3 a a}$ in 93\% yield ( $1.03 \mathrm{~g}$; for details, see the Supplementary Material). This result underscores the high practical utility of this protocol. Even when the reaction was carried out under a nitrogen atmosphere, the product yield was not improved. This indicates that air (oxygen and $\mathrm{CO}_{2}$ ) in the reaction vessel does not significantly affect the efficiency of this protocol.

Substrate scope of the nucleophilic addition to aldehydes and ketones. With the optimized conditions (conditions A) in hand, we proceeded to investigate the substrate scope for the nucleophilic addition to aldehydes and ketones (Fig. 2). Our results show that this method is characterized by a broad substrate scope that encompasses aromatic and aliphatic bromides $(\mathbf{1 a}-\mathbf{1 e})$, aldehydes ( $2 \mathbf{a}-\mathbf{2 c}$ and $\mathbf{2 f}$ ), and ketones ( $\mathbf{2 d}$ and $2 \mathbf{e}$ ) to give the desired alcohols (3aa-3ef) in moderate to high yields. Furthermore, this method was also applicable to aryl halides that bear various substituents such as methoxy- and dimethylamino groups in para- and ortho-position (for details, see the Supplementary Material). To improve the yield of $\mathbf{3}$, we also tested the use of an excess of magnesium (5.0 equiv) or organic halide (2.0 equiv) (conditions B). Although conditions B generally provided product yields comparable to those achieved using conditions A, conditions B improved the efficiency of the reactions using secondary 
a. Grignard reagents: Fundamentally indispensable reagents in organic synthesis

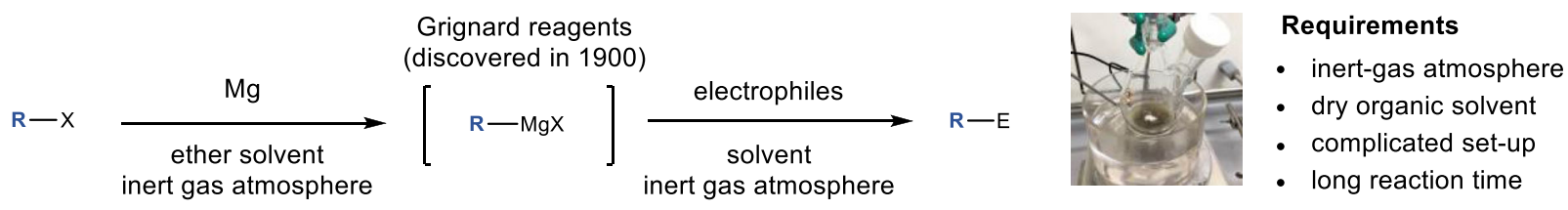

b. Attempts at mechanochemical reactions between Mg and aryl halides: Harrowfield (2001), Brike (2009, 2011), Hanusa (2020)

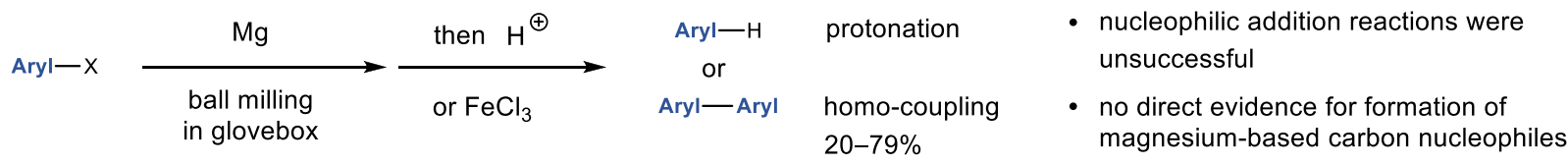

c. This work: Mechanochemical synthesis of magnesium-based carbon nucleophiles

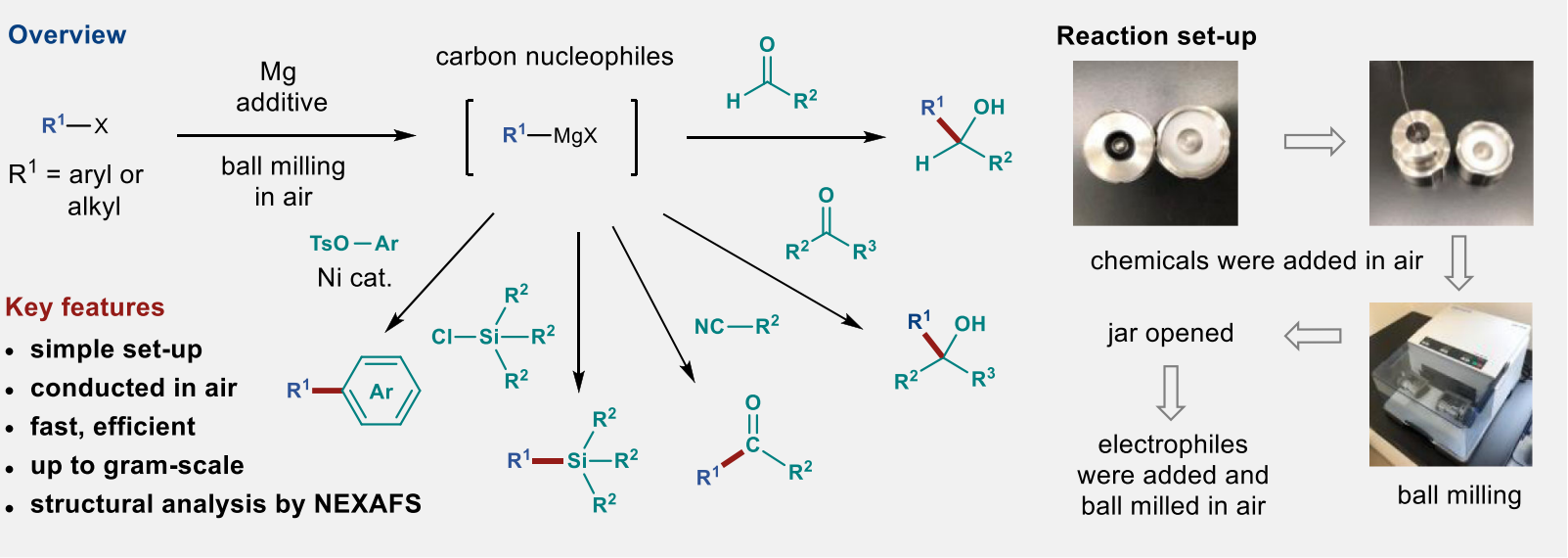

\section{d. Optimization study for the formation of magnesium-based nucleophile}

\begin{tabular}{|c|c|c|c|c|}
\hline \multirow{2}{*}{$\mathrm{Ph}-$} & \multirow{2}{*}{\multicolumn{2}{|c|}{$\begin{array}{l}\mathrm{Mg}(1.5 \text { equiv) } \\
\text { additive ( } 3.0 \text { equiv) }\end{array}$}} & \multirow{3}{*}{$\begin{array}{c}\text { additive } \\
\text { (3.0 equiv) }\end{array}$} & \multirow{3}{*}{$\begin{array}{l}\text { yield of } \\
\text { 3aa }(\%)\end{array}$} \\
\hline & & & & \\
\hline & \multirow{2}{*}{$\begin{array}{l}\text { ball milling }(30 \mathrm{~Hz}) \\
60 \mathrm{~min} \text {, in air }\end{array}$} & \multirow{2}{*}{$\begin{array}{c}\mathrm{Ph}-\mathrm{MgBr} \\
\text { opening jar } \\
\text { one-pot }\end{array}$} & & \\
\hline $\begin{array}{c}1 \mathrm{a} \\
1.5 \text { equiv }\end{array}$ & & & none & 6 \\
\hline & & & THF & 94 \\
\hline & & & $\mathrm{Et}_{2} \mathrm{O}$ & 79 \\
\hline & $\begin{array}{l}\text { ball milling ( } \\
60 \mathrm{~min} \text {, in a }\end{array}$ & & $\begin{array}{l}\text { CPME } \\
\text { hexane }\end{array}$ & $\begin{array}{l}87 \\
1\end{array}$ \\
\hline
\end{tabular}

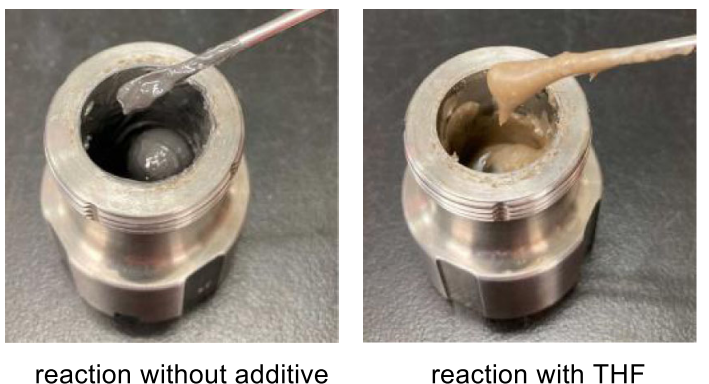

Fig. 1 Synthesis of organomagnesium nucleophiles using mechanochemistry and their application to organic synthesis. a Conventional solution-based method for the preparation of Grignard reagents. b Previous attempts to mechanochemically synthesize organomagnesium nucleophiles. c Mechanochemical synthesis of organomagnesium nucleophiles and their application to organic synthesis. $\mathbf{d}$ Optimization study for the formation of magnesium-based nucleophiles using ball milling.

alkyl bromide 1e, affording the products $3 \mathbf{e a}-3 \mathbf{e f}$ in moderate to good yields. The addition of lithium salts has slightly improved the yields of 3aa-3ae and 3ca-3ce (for details, the Supplementary Material). We also attempted the reactions using the liquid substrates in a test tube with efficient mixing by magnetic stirring under the optimized conditions, but these reactions resulted in poor or almost no product formation (for details, the Supplementary Material). These results suggest that strong mechanical agitation in the ball mill is crucial for the formation of the magnesium-based carbon nucleophiles ${ }^{30}$.

Mechanochemical synthesis of magnesium-based carbon nucleophiles from solid aryl halides. We found that attempts to react magnesium and solid aryl halides such as 4-bromobiphenyl (1f) for the subsequent nucleophilic addition to benzaldehyde (2a) resulted in almost no reaction under the optimized conditions (conditions A or B). Neither prolonging the reaction time nor using liquid additives improved the yield of the product (3fa). To promote the formation of magnesium-based nucleophiles from the solid aryl halides, we decided to carry out the reaction at higher temperature. In one of our previous studies, we revealed that external heating enables poorly soluble aryl halides to react in solid-state cross-coupling reactions ${ }^{31}$. In that case, external heating may help to weaken the intermolecular interactions of solid substrates, which would improve the mixing efficiency and promote chemical reactions. Specifically, we placed a 


$$
\begin{aligned}
& \text { one-pot two-step protocol }
\end{aligned}
$$

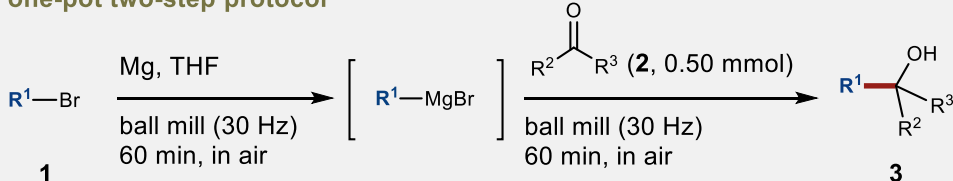

\section{conditions A}

electrophile (1.0 equiv), halide (1.5 equiv) $\mathrm{Mg}$ (1.5 equiv), and THF ( 3.0 equiv)

\section{conditions B}

electrophile ( 1.0 equiv), halide (2.0 equiv) $\mathrm{Mg}$ (5.0 equiv), and THF (3.0 equiv)


2a<smiles>O=CCCc1ccccc1</smiles>

2b<smiles>O=CC1CCCCC1</smiles>

2c<smiles>CCC(=O)c1ccccc1</smiles>

2d<smiles>C=C(C)CCc1ccccc1</smiles>

$2 e$<smiles>O=Cc1ccc2ccccc2c1</smiles>

2f

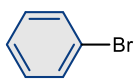

1a

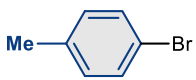

$1 \mathrm{~b}$

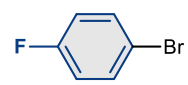

$1 \mathrm{c}$

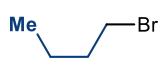

1d

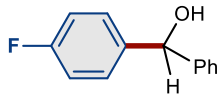

$3 \mathrm{ca}$

A: $77 \%(81 \%)$

B: $67 \%(75 \%)$ with $\mathrm{LiCl}$ $\begin{array}{ll}\text { A: } 84 \%(94 \%) & \text { A: } 86 \%(91 \%) \\ \text { B: } 64 \%(75 \%) & \text { B: } 56 \%(78 \%)\end{array}$

with $\mathrm{LiBr}$

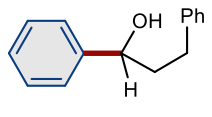

$3 a b$

A: $70 \%(84 \%)$

B: $63 \%$ with $\mathrm{LiBr}$

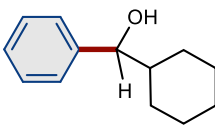

3ac

A: $73 \%(75 \%)$

B: $58 \%(67 \%)$ with $\mathrm{LiCl}$

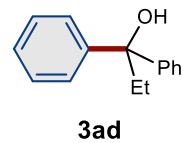

A: $82 \%(88 \%)$

B: $45 \%(63 \%)$

with $\mathrm{LiBr}$

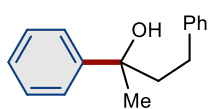

3ae

A: $79 \%(83 \%)$

B: $69 \%(82 \%)$

with $\mathrm{LiBr}$

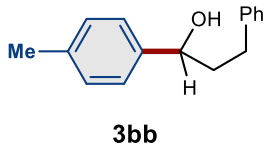

A: $70 \%(86 \%)$
B: $42 \%(61 \%)$

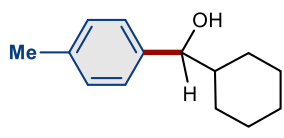

3 bc

A: $62 \%(66 \%)$

B: $55 \%(68 \%)$

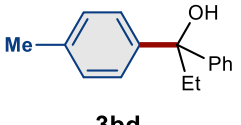

A: $74 \%(80 \%)$

B: $64 \%(70 \%)$

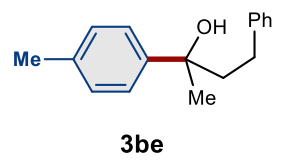

A: $69 \%(72 \%)$

B: $60 \%(85 \%)$

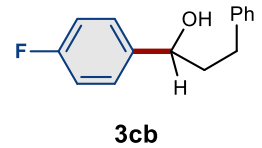

A: $70 \%(81 \%)$

B: $61 \%$ with $\mathrm{LiCl}$

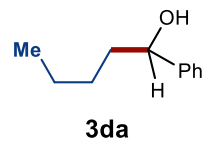

A: $73 \%(90 \%)$

B: $77 \%(92 \%)$

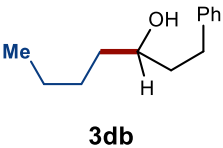

A: $46 \%(62 \%)$

B: $62 \%$

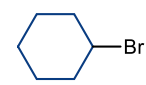

$1 e$

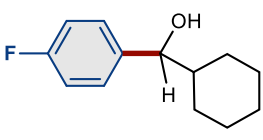

$3 \mathrm{cc}$

A: $62 \%(70 \%)$

B: $55 \%(62 \%)$ with $\mathrm{LiCl}$

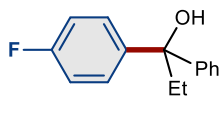

3cd

A: $71 \%(71 \%)$

B: $61 \%(74 \%)$ with $\mathrm{LiCl}$

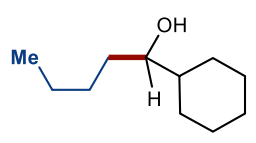

3 dc

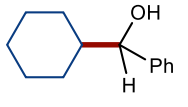

3 ea

A: $(24 \%)$

B: $58 \%(74 \%)$

A: $67 \%(70 \%)$

B: $55 \%(67 \%)$

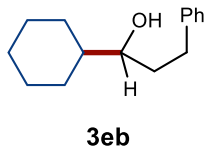

A: $40 \%$ B: $42 \%(50 \%)$
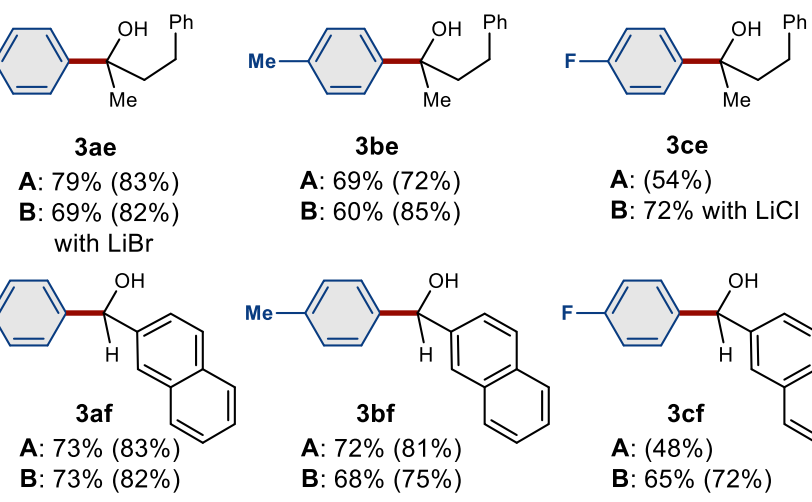

A: $(54 \%)$

B: $72 \%$ with $\mathrm{LiCl}$
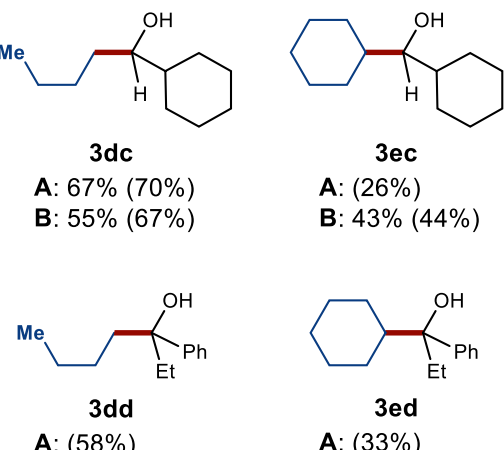

3 ec

A: $(26 \%)$

B: $43 \%(44 \%)$

B: $60 \%(71 \%)$

A: $(33 \%)$

B: $30 \%(41 \%)$
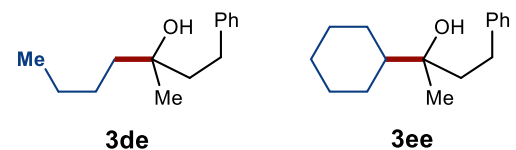
A: $(66 \%)$
A: $15 \%$
B: $63 \%(77 \%)$
B: $22 \%(38 \%)$
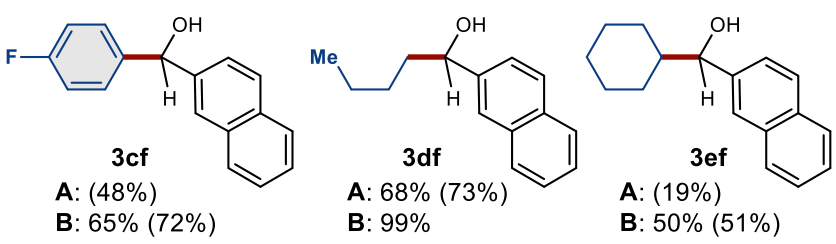

Fig. 2 Scope of the mechanochemical synthesis of organomagnesium nucleophiles and their nucleophilic addition to aldehydes and ketones in a ball mill. A stainless-steel milling jar $(5 \mathrm{~mL}$ ) and stainless-steel ball (diameter: $10 \mathrm{~mm}$ ) were used. Isolated yields are reported as percentages. Proton NMR integrated yields are shown in parentheses. For details, see the Supplementary Information.

commercially available, temperature-controllable heat gun directly above the ball-milling jar ${ }^{31}$. The mechanochemical reactions between magnesium and the solid aryl halides were conducted while applying hot air to the outside of the milling jar. We set the temperature of the heat gun to $110^{\circ} \mathrm{C}$ in order to ensure an internal reaction temperature of $70{ }^{\circ} \mathrm{C}$, which was confirmed by thermography immediately after opening the milling jar (Fig. 3a). The reaction between magnesium and $\mathbf{1 f}$ in the presence of THF (3.0 equiv) was complete within $1 \mathrm{~h}$ and formed the desired nucleophilic product (3fa) in high yield (75\%). In this 
a. Reactions of simple solid aryl bromides

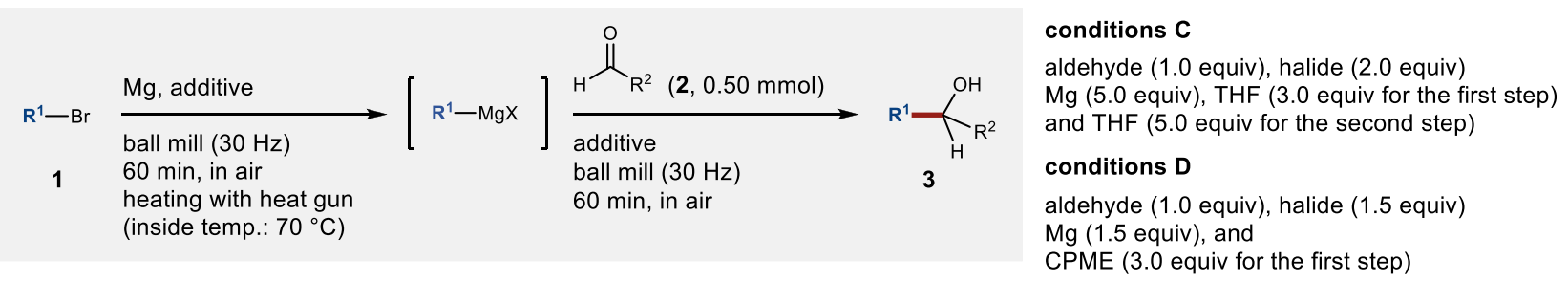

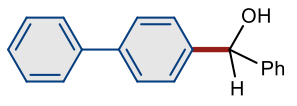

$3 \mathrm{fa}$

C: $75 \%(93 \%)$

D: $76 \%(80 \%)$

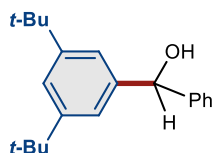

3ha

C: $75 \%$

D: $(35 \%)$

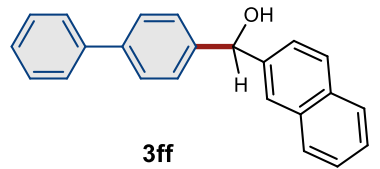

C: $76 \%(81 \%)$

D: $60 \%(72 \%)$

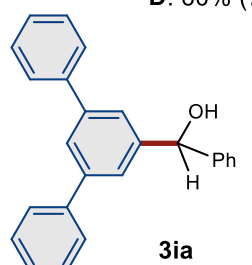

C: $82 \%$

D: $(61 \%)$

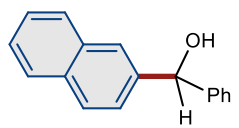

3ga

C: $77 \%$

D: $(61 \%)$

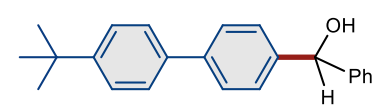

3ja

D: $<1 \%$

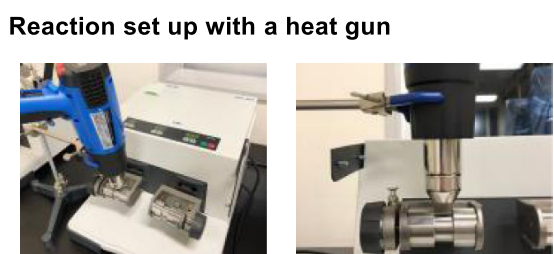

Thermographic analysis

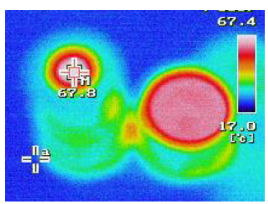

1f, $\mathrm{Mg}$ and THF were milled for $60 \mathrm{~min}$ internal temp.: $68^{\circ} \mathrm{C}$ preset temp.: $110{ }^{\circ} \mathrm{C}$

b. Reactions of poorly soluble aryl bromides

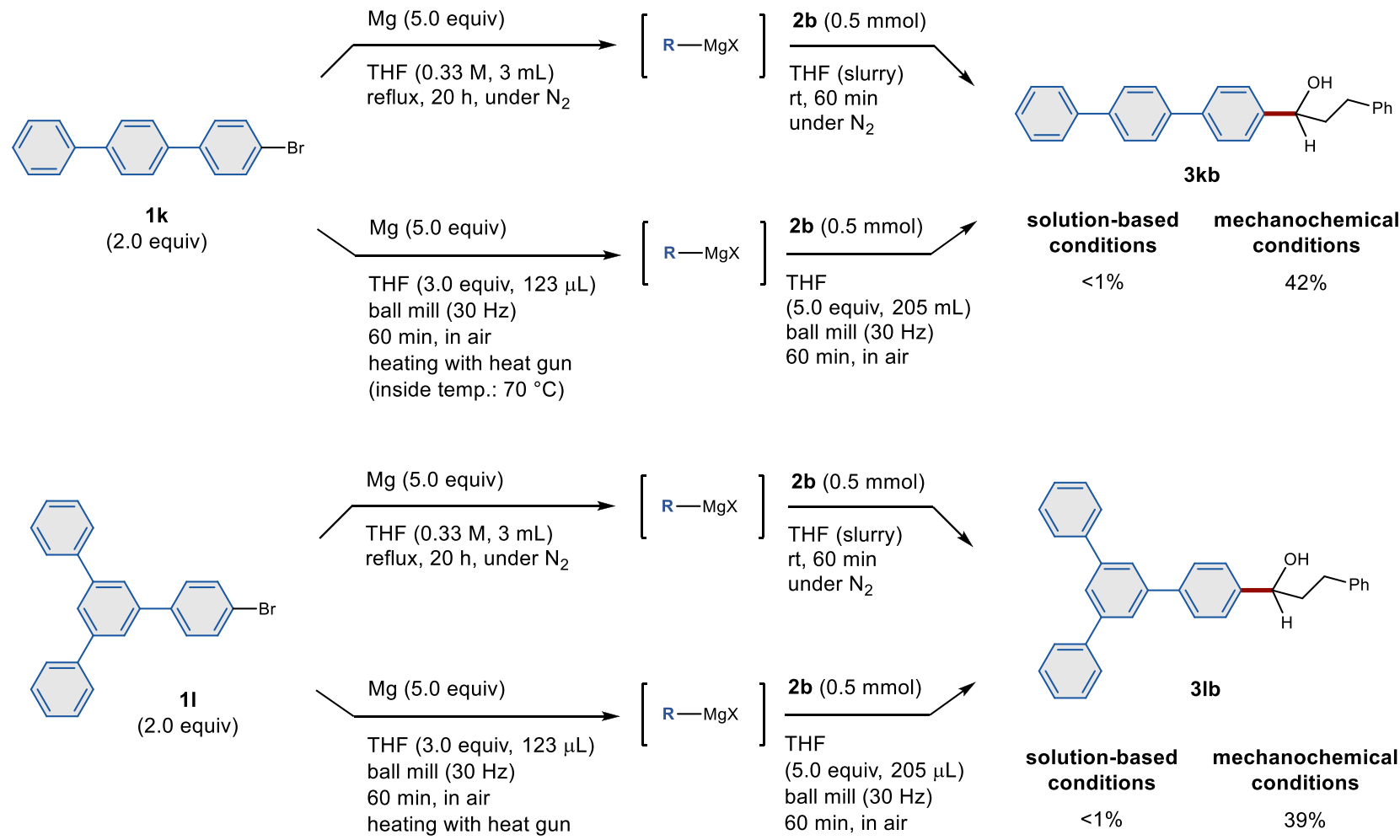

Fig. 3 Synthesis of organomagnesium nucleophiles via a high-temperature ball-milling technique. A stainless-steel milling jar ( $5 \mathrm{~mL}$ ) and stainless-steel ball (diameter: $10 \mathrm{~mm}$ ) were used; for details, see the Supplementary Information. Isolated yields are reported as percentages. Proton NMR integrated yields are shown in parentheses. a Mechanochemical synthesis of magnesium-based carbon nucleophiles from solid aryl halides. b Mechanochemical conditions allowed the formation of magnesium-based carbon nucleophiles from poorly soluble aryl halides $\mathbf{1 k}$ and $\mathbf{1 1}$, which are not readily applicable to the conventional solution-based protocol. 
procedure, THF (5.0 equiv) was added for the nucleophilic addition step, which improved the yield of $\mathbf{3} \mathbf{f a}$. These high-temperature ball-milling conditions (conditions $\mathrm{C}$ ) were applied to various solid bromides $(\mathbf{1 f}-\mathbf{1 j})$ and afforded the corresponding alcohols (3ff-3ja) in high yield. The use of CPME instead of THF provided comparable yields of the addition products (conditions D).

Reactions of $\mathrm{Mg}$ metal with poorly soluble aryl halides under conventional solution-based conditions are often inefficient. For example, the reaction of poorly soluble 4-bromoterphenyl (1k) as a slurry under reflux conditions (309.2 $\mathrm{mg}$ of $\mathbf{1 k}$ in $3 \mathrm{~mL}$ of THF, $0.33 \mathrm{M}$, for $20 \mathrm{~h}$ ) did not afford any nucleophilic addition product (Fig. 3b). We also attempted using more dilute conditions (309.2 $\mathrm{mg}$ of $\mathbf{1 k}$ in $15 \mathrm{~mL}$ of THF, $0.067 \mathrm{M}$, for $20 \mathrm{~h}$ ), albeit that $3 \mathbf{k b}$ was still not obtained. In contrast, the developed mechanochemical conditions provided the corresponding magnesiumbased carbon nucleophile from $\mathbf{1 k}$ via high-temperature ball milling within $1 \mathrm{~h}$, and the desired nucleophilic addition product (3kb) was obtained in moderate yield (42\%). Furthermore, poorly soluble $\mathbf{1 1}$ was also reactive under the solid-state conditions and formed the desired addition product (3lb) in 39\% yield, while $\mathbf{3 l b}$ was not obtained under solution-based conditions. These results demonstrate the potential of this mechanochemical protocol as an operationally simple and efficient route to synthesize magnesiumbased carbon nucleophiles from poorly soluble substrates that are incompatible with conventional solution-based conditions.

Applications of mechanochemically generated organomagnesium nucleophiles to various organic transformations. The mechanochemically synthesized organomagnesium nucleophiles were applicable to reactions with various organic electrophiles (Fig. 4a). A Weinreb amide (4a) and ester (4b) were converted to the corresponding ketone (5a) and tertiary alcohol $(\mathbf{5 b})$ in good yield. Nitrile (4c) reacted with the organomagnesium nucleophile derived from $1 \mathbf{d}$ even at room temperature to provide the desired ketone $(\mathbf{5 c})$ in moderate yield. Other $\mathrm{C}-\mathrm{C}$-bond-forming reactions with carbon dioxide, epoxides, and amides afforded the corresponding products in low to good yield (for details, see the Supplementary Material). In addition, the organomagnesium reagents were applicable to not only $\mathrm{C}-\mathrm{C}$-bond-formation reactions but also to $\mathrm{Si}-\mathrm{C}$-bond-formation reactions with chlorosilane $(\mathbf{4 d})$ in the presence of a catalytic amount of copper iodide ${ }^{32}$.

Next, we investigated nickel-catalyzed Kumada-Tamao-Corriu coupling reactions between the mechanochemically synthesized organomagnesium nucleophiles and aryl tosylates under ballmilling conditions (Fig. 4b) ${ }^{33}$. After the formation of the organomagnesium reagent generated from 1d, the jar was opened in air and 2-naphthyl tosylate (6a) and $10 \mathrm{~mol} \%$ of (dppe) $\mathrm{NiCl}_{2}$ were added quickly. The subsequent ball-milling reaction afforded cross-coupling product $7 \mathbf{a}$ in 35\% NMR yield (conditions $\mathrm{H}$ ). We found that increasing the amounts of $\mathbf{1 d}$, magnesium, and THF improved the yield of $7 \mathbf{a}$ to $75 \%$ (conditions I). Under conditions I, reactions with simple naphthyl tosylates gave the desired products ( $7 \mathbf{b}$ and $7 \mathbf{c}$ ) in high yield (70\% and $88 \%$, respectively). However, 7d, i.e., the product derived from naphthyl tosylate bearing a methoxy group $(\mathbf{6 c})$, was obtained in relatively low yield (36\%), while the product bearing a fluoride atom (7e) was obtained in good yield $(79 \%)$. A variety of primary and secondary alkyl bromides were applicable to these mechanochemical crosscoupling reactions $(\mathbf{7 f}-\mathbf{7 i})$. To the best of our knowledge, this is the first example of Kumada-Tamao-Corriu cross-coupling reactions under mechanochemical conditions.

Nucleophilic addition reactions of the mechanochemically synthesized organomagnesium nucleophiles to conjugated enone 8 were also examined (Fig. 4c). The reaction of the phenyl magnesium reagent with benzylidene acetone (8) in THF solution at room temperature afforded a mixture of the 1,2-addition product (9) and the 1,4-addition product $(\mathbf{9} / \mathbf{1 0}=75: 25)$. Interestingly, the selectivity toward 1,2-addition increased under mechanochemical conditions $(\mathbf{9} / \mathbf{1 0}=88: 12)$. Furthermore, the mechanochemical nucleophilic addition in the presence of $\mathrm{CuI}$ afforded the 1,4-addition product (10) with high selectivity (50\%; $\mathbf{9} / \mathbf{1 0}=8: 92)$, suggesting that the corresponding cuprate might be formed even under mechanochemical conditions. The addition of $\mathrm{CeCl}_{3}$ did not influence the selectivity under the mechanochemical conditions $(43 \% ; \mathbf{9} / \mathbf{1 0}=86: 14)$, while under the corresponding solution-based conditions, $\mathrm{CeCl}_{3}$ improved the selectivity toward the 1,2-addition product 34,35 .

Confirmation of the formation of magnesium-based carbon nucleophiles under ball-milling conditions. In order to confirm the generation of magnesium-based carbon nucleophiles under ball-milling conditions, a deuterium-labeling experiment was conducted (for details, see the Supplementary Material). 3,5-Ditert-butylphenyl bromide (1h) was treated with magnesium under the optimized conditions, the jar was opened, and $\mathrm{CD}_{3} \mathrm{CO}_{2} \mathrm{D}$ was added quickly. The subsequent ball-milling reaction furnished deuterium-labeled 1,3-di-tert-butylbenzene 11 (>99\% D), which suggests that the corresponding magnesium-based carbon nucleophile is formed.

Furthermore, near-edge X-ray absorption fine structure (NEXAFS) spectroscopy was used to analyze the generation of magnesium-based carbon nucleophiles under mechanochemical conditions (Fig. 5). The NEXAFS measurements were carried out at UVSOR synchrotron facility (Japan) using the magnesiumbased carbon nucleophile 12, which was prepared by ball milling and transferred into the soft X-ray optics under an argon atmosphere (Fig. 5a). The formation of the divalent cationic $\mathrm{Mg}^{2+}$ species was unequivocally confirmed by the high-energy shift of the $\mathrm{Mg} \mathrm{K}$-absorption edge $(1307.4 \mathrm{eV})$ relative to the $\mathrm{Mg}^{0}$ edge $(1302.6 \mathrm{eV})$ of a standard magnesium flake (Fig. 5b) ${ }^{36}$. The high similarity of $\mathrm{Mg}-\mathrm{K}$ and $\mathrm{C}-\mathrm{K}$ NEXAFS spectra of mechanochemically-prepared $\mathbf{1 2}$ and $\mathrm{PhMgBr}$ prepared in solution (Figs. 5b, c) supports the formation of similar organomagnesium species that possess a carbon-magnesium bond under both ball-milling and solution conditions in THF. The intense $1 \mathrm{~s}-\pi^{*}$ transition peaks ${ }^{37}$ at 285.7 and $287.7 \mathrm{eV}$ in the C-K NEXAFS spectra also support the formation of a carbon-magnesium bond resulting from the transformation of the $\mathrm{C}-\mathrm{Br}$ bond of the starting bromobenzene (for details, see the Supplementary Material). A preliminary theoretical study was also carried out to predict the structure of the magnesium-based carbon nucleophiles prepared by ball-milling (for details, see Supplementary Fig. 13).

\section{Discussion}

The present mechanochemical synthesis of magnesium-based carbon nucleophiles and their reactions with various electrophiles can be carried out in air without the need for large amounts of dry and degassed solvent(s), special precautions, or synthetic techniques. In addition to these advantages, solid-state ball-milling conditions enabled the synthesis of magnesium-based carbon nucleophiles from poorly soluble aryl halides that are incompatible with conventional solution-based conditions. This can expand the utility of Grignard reagents. Direct spectroscopic evidence for the formation of magnesium-based carbon nucleophiles under mechanochemical conditions was obtained using NEXAFS spectroscopy. Given the widespread use of Grignard reagents in modern organic chemistry, we anticipate that this approach will inspire the development of attractive synthetic applications to complement existing solution-based technologies. 
a. Nucleophilic addition to various organic electrophiles

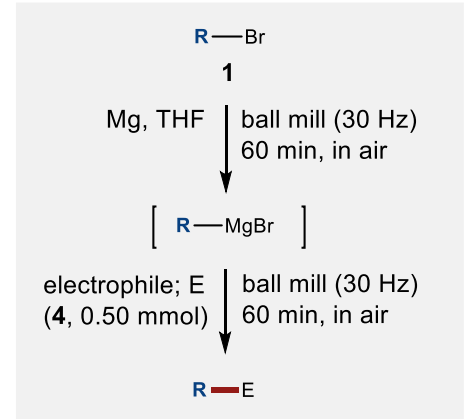

\section{conditions $\mathrm{E}$}

electrophile (1.0 equiv), halide ( 1.5 equiv) $\mathrm{Mg}$ ( 1.5 equiv), and THF ( 3.0 equiv)

\section{electrophiles}<smiles>CON(C)C(=O)c1ccccc1</smiles>

$4 a$<smiles>CCCCC(=O)c1ccccc1</smiles>

$5 \mathbf{a}$
E: $(60 \%)$

$$
\text { F: } 53 \%(69 \%)
$$

\section{conditions $\mathbf{F}$}

electrophile ( 1.0 equiv), halide ( 2.0 equiv) $\mathrm{Mg}$ (5.0 equiv), and THF (3.0 equiv)<smiles>COC(=O)c1ccccc1</smiles>

4b<smiles>CCCCC(O)(CCCC)c1ccccc1</smiles>

$5 b$
G: $61 \%(73 \%)$<smiles>CCCCC(=O)c1ccc2ccccc2c1</smiles>

E: $(40 \%)$

F: $52 \%$<smiles>N#Cc1ccc2ccccc2c1</smiles>

4c<smiles>C[Si](C)(Cl)c1ccccc1</smiles>

4d

\section{conditions G}

electrophile ( 1.0 equiv), halide (3.0 equiv) $\mathrm{Mg}$ (3.0 equiv), and THF (6.0 equiv)

\section{b. Nickel-catalyzed Kumada-Tamao-Corriu coupling}

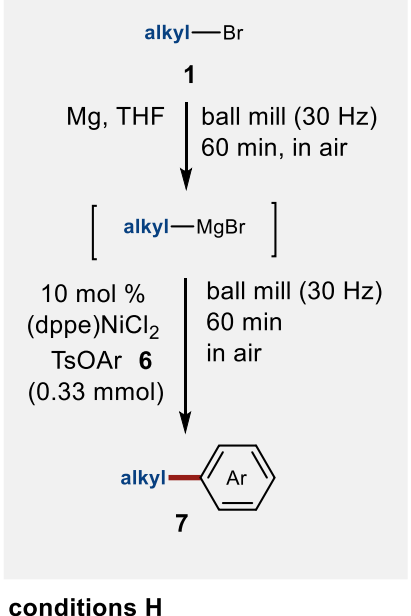

conditions $\mathrm{H}$

tosylate (1.0 equiv), halide (1.5 equiv) $\mathrm{Mg}$ ( 1.5 equiv), and THF (3.0 equiv)<smiles>CCCCc1ccc2ccccc2c1</smiles>

$7 \mathbf{a}$

H: $(35 \%)$, I: $75 \%$<smiles>CCCCc1ccc2cc(OC)ccc2c1</smiles>

7d

H: $(26 \%), \mathbf{I}: 36 \%$<smiles>COCCCCc1ccc2ccccc2c1</smiles>

$\mathbf{7 g}$

H: $(21 \%)$, I: $87 \%$

\section{conditions I}

tosylate (1.0 equiv), halide (3.0 equiv)

$\mathrm{Mg}$ ( 7.5 equiv), and THF (4.5 equiv)

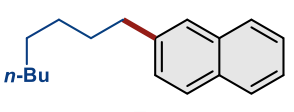

7c
$7 \mathbf{b}$

H: $(44 \%)$, I: $70 \%$

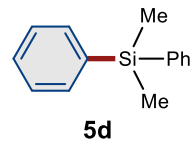

E: $62 \%$ (with Cul)

F: $46 \%$ (with Cul)

H: $(31 \%)$, I: $88 \%(99 \%)$

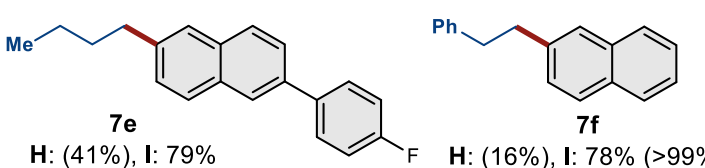

H: $(16 \%)$, I: $78 \%(>99 \%)$<smiles>CC(C)(C)Cc1ccc2ccccc2c1</smiles>

7h

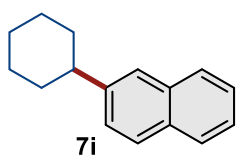

H: $<1 \%$, I: $40 \%(53 \%)$
NMR yield of conditions additive $\quad \mathbf{9 + 1 0}(\mathbf{9 : 1 0})(\%)$

THF solution none $100 \%(75: 25)$

ball mill none J: $64 \%(88: 12)$

K: $67 \%(88: 12)$

ball mill Cul L: $50 \%(8: 92)$

ball mill $\quad \mathrm{CeCl}_{3} \quad \mathbf{M}: 43 \%(86: 14)$ enone (1.0 equiv), halide ( 1.5 equiv) $\mathrm{Mg}$ (1.5 equiv), and THF (3.0 equiv)

conditions $L$

enone ( 1.0 equiv), halide ( 4.0 equiv)

$\mathrm{Mg}$ (4.0 equiv), Cul (2.0 equiv), and THF (8.0 equiv)

\section{conditions $\mathrm{K}$}

enone ( 1.0 equiv), halide ( 2 equiv) $\mathrm{Mg}$ (5 equiv), and THF ( 3 equiv)

\section{conditions $M$}

$\mathrm{Mg}$ (1.5 equiv), $\mathrm{CeCl}_{3}$ (1.5 equiv), amd THF (3.0 equiv)

Fig. 4 Various organic transformations using mechanochemically generated organomagnesium nucleophiles. Isolated yields are reported as percentages. Proton NMR integrated yields are shown in parentheses. a Nucleophilic addition to various electrophiles under mechanochemical conditions. $\mathbf{b}$ Mechanochemical nickel-catalyzed Kumada-Tamao-Corriu coupling reactions. c Nucleophilic addition reactions to conjugated enone $\mathbf{8}$ under mechanochemical conditions. A stainless-steel milling jar $(5 \mathrm{~mL}$ ) and a stainless-steel ball (diameter: $10 \mathrm{~mm}$ ) were used. For details, see the Supplementary Information. 


\section{a. NEXAFS analysis of 12 prepared under mechanochemical conditions}

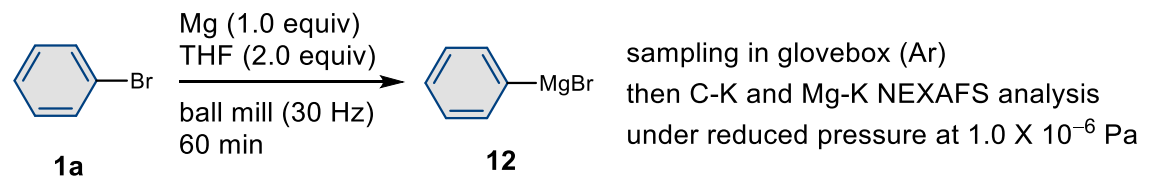

b. Mg K-edge NEXAFS spectra of 12 and $\mathrm{PhMgBr}$ in THF

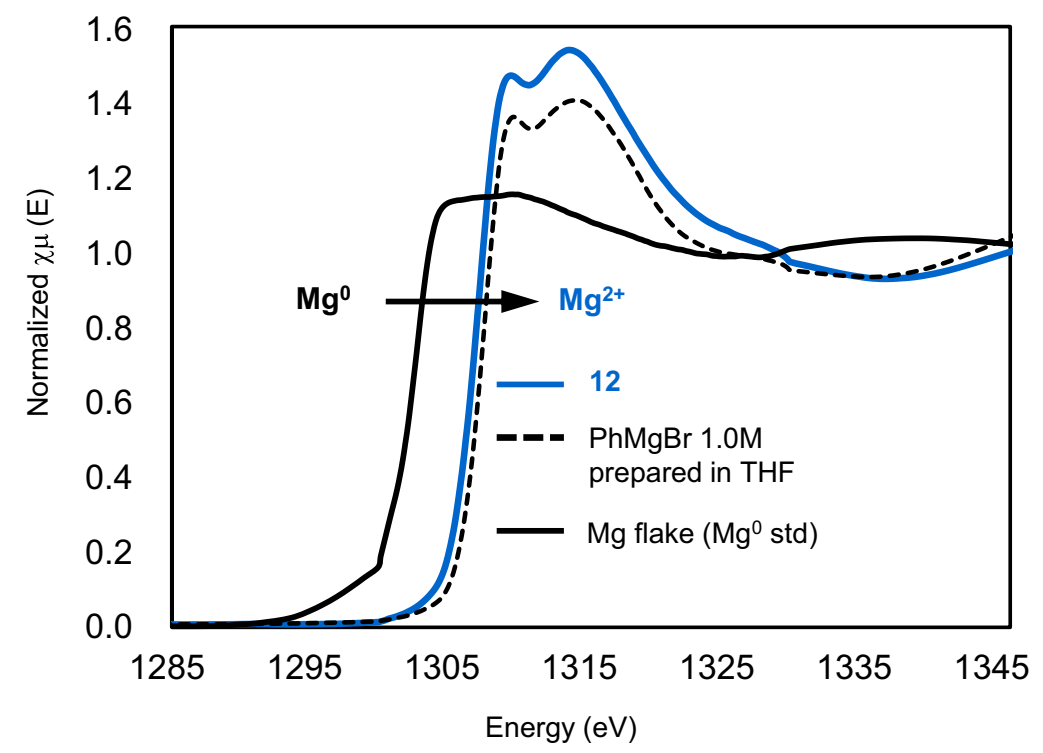

c. C K-edge NEXAFS spectra of 12 and PhMgBr in THF

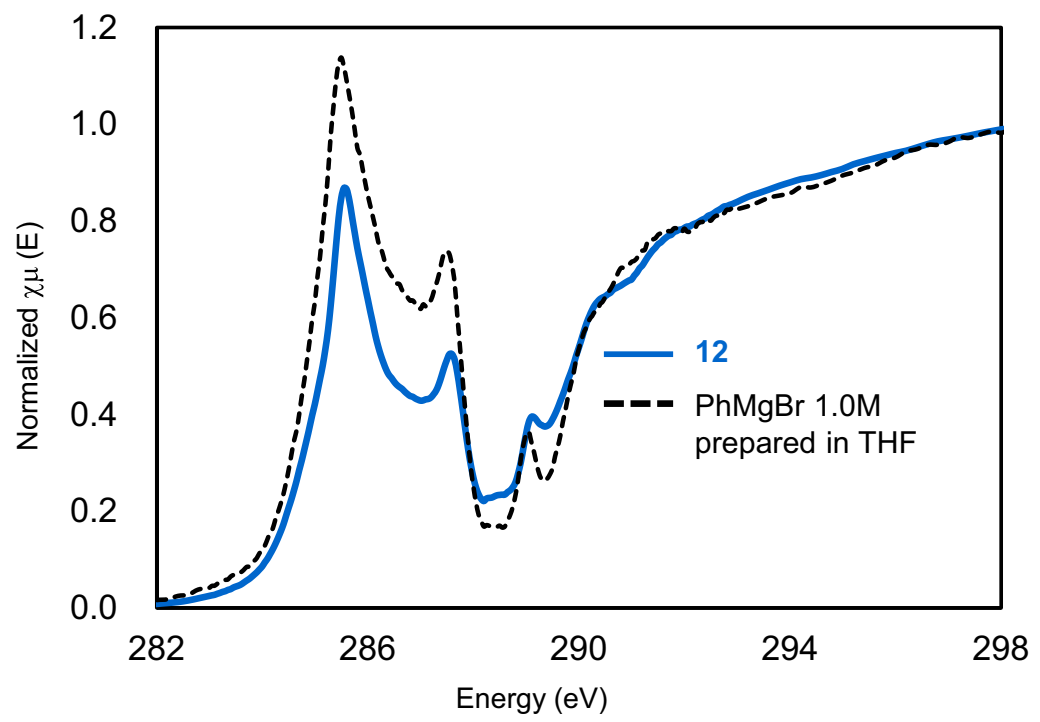

Fig. 5 NEXAFS analysis of a magnesium-based carbon nucleophile under mechanochemical conditions. a Preparation of a sample of magnesium-based carbon nucleophile $\mathbf{1 2}$ under mechanochemical conditions. b Mg K-edge NEXAFS spectra of mechanochemically prepared 12, $\mathrm{PhMgBr}$ prepared in solution, and a magnesium flake of a $\mathrm{Mg}^{0}$ standard. c C K-edge NEXAFS spectra of mechanochemically prepared $\mathbf{1 2}$ and $\mathrm{PhMgBr}$ prepared in solution.

Shortly after our submission, the Bolm group reported mechanochemical Grignard reactions with gaseous $\mathrm{CO}_{2}$, which afford the corresponding carboxylic acids in moderate to good yield ${ }^{38}$. The development of Minischi-type reactions using magnesium under ball-milling conditions, which is related to our present study, has also been reported ${ }^{39}$

\section{Methods}

Representative procedure for the solvent-less synthesis of magnesium-based carbon nucleophiles and their reactions with electrophiles. Mg turnings $(0.75 \mathrm{mmol}, 1.5$ equiv) were placed in a jar (stainless steel; $5 \mathrm{~mL})$ with a ball (stainless steel; $10 \mathrm{~mm}$, diameter) in air. An organic bromide $\mathbf{1}(0.75 \mathrm{mmol}, 1.5$ equiv) and THF ( $123 \mu \mathrm{L}, 1.5 \mathrm{mmol}, 3.0$ equiv) were added to the jar using a syringe. After the jar was closed without purging with inert gas, the jar was placed in a ball mill (Retsch MM 400, $60 \mathrm{~min}, 30 \mathrm{~Hz}$ ). After grinding for $60 \mathrm{~min}$, the jar was 
opened in air and charged with an electrophile $2(0.50 \mathrm{mmol})$. The jar was then closed without purging with inert gas, and was placed in the ball mill (Retsch MM $400,60 \mathrm{~min}, 30 \mathrm{~Hz}$ ). After grinding for $60 \mathrm{~min}$, the reaction mixture was quenched with a saturated aqueous solution of $\mathrm{NH}_{4} \mathrm{Cl}$ and extracted with $\mathrm{CH}_{2} \mathrm{Cl}_{2}(30 \mathrm{~mL} \times 3)$. The solution was washed with brine and dried over $\mathrm{Na}_{2} \mathrm{SO}_{4}$. After the removal of the solvents under reduced pressure, the crude material was purified by flash column chromatography $\left(\mathrm{SiO}_{2}\right.$, hexane/ethyl acetate, 100:0 to 80:20) to give the corresponding product 3 .

\section{Data availability}

For full characterization data including NMR spectra of the new compounds and experimental details, see the Supplementary Material. All relevant data underlying the results of this study are available from the corresponding authors upon request.

Received: 16 July 2021; Accepted: 27 October 2021;

Published online: 18 November 2021

\section{References}

1. Grignard, V. Some new organometallic combinations of magnesium and their application to the synthesis of alcohols and hydrocarbons. C. R. Acad. Sci. 130, $1322-1325$ (1900)

2. Silverman, G. S. \& Rakita, P. E. (eds) Handbook of Grignard Reagents (Marcel Dekker, 1996).

3. Richey, H. G. (ed) Grignard Reagents: New Developments (Wiley, 2000).

4. Banno, T., Hayakawa, Y. \& Umeno, M. Some applications of the Grignard cross-coupling reaction in the industrial field. J. Organomet. Chem. 653, 288-291 (2002).

5. Knochel, P. (ed) Handbook of Functionalized Organometallics: Applications in Synthesis (Wiley-VCH, 2005).

6. Seyferth, D. The Grignard reagents. Organometallics 28, 1598-1605 (2009).

7. Knochel, P. in Organometallics in Synthesis - Third Manual (ed. Schlosser, M.) 223-372 (Wiley, 2013).

8. Nagaki, A. \& Yoshida, J. in Organometallic Flow Chemistry (ed. Noël, T.) 137-175 (Springer, 2016)

9. Trost, B. M. The atom economy-a search for synthetic efficiency. Science $\mathbf{2 5 4}$, 1471-1477 (1991).

10. Teerlinck, C. E. \& Bowyer, W. J. Reactivity of magnesium surfaces during the formation of Grignard reagents. J. Org. Chem. 61, 1059-1064 (1996).

11. Einhorn, C., Einhorn, J. \& Luche, J.-L. Sonochemistry-the use of ultrasonic waves in synthetic organic chemistry. Synthesis 11, 787-813 (1989).

12. Gold, H., Larhed, M. \& Nilsson, P. Microwave irradiation as a high-speed tool for activation of sluggish aryl chlorides in Grignard reactions. Synlett 10 1596-1600 (2005).

13. Lai, Y.-H. Grignard reagents from chemically activated magnesium. Synthesis 8, 585-604 (1981)

14. Tilstam, U. \& Weinmann, H. Activation of Mg metal for safe formation of Grignard reagents on plant scale. Org. Process Res. Dev. 6, 906-910 (2002).

15. Piller, F. M., Appukkuttan, P., Gavryushin, A., Helm, M. \& Knochel, P. Convenient preparation of polyfunctional aryl magnesium reagents by a direct magnesium insertion in the presence of LiCl. Angew. Chem. Int. Ed. 47, 6802-6806 (2008).

16. James, S. L. et al. Mechanochemistry: opportunities for new and cleaner synthesis. Chem. Soc. Rev. 41, 413-447 (2012).

17. Do, J.-L. \& Friščić, T. Mechanochemistry: a force of synthesis. ACS Cent. Sci. 3, 13-19 (2017).

18. Hernández, J. G. \& Bolm, C. Altering product selectivity by mechanochemistry. J. Org. Chem. 82, 4007-4019 (2017).

19. Kubota, K. \& Ito, H. Mechanochemical cross-coupling reactions. Trends Chem. 2, 1066-1081 (2020).

20. Howard, J. L., Cao, Q. \& Browne, D. L. Mechanochemistry as an emerging tool for molecular synthesis: what can it offer? Chem. Sci. 9, 3080-3094 (2018).

21. Tan, D. \& García, F. Main group mechanochemistry: from curiosity to established protocols. Chem. Soc. Rev. 48, 2274-2292 (2019).

22. Bolm, C. \& Hernández, J. G. Mechanochemistry of gaseous reactants. Angew. Chem. Int. Ed. 58, 3285-3299 (2019).

23. Porcheddu, A., Colacino, E., De Luca, L. \& Delog, F. Metal-mediated and metal-catalyzed reactions under mechanochemical conditions. ACS Catal. 10, 8344-8394 (2020).

24. Kaupp, G. Mechanochemistry: the varied applications of mechanical bondbreaking. CrystEngComm 11, 388-403 (2009).

25. Harrowfield, J. M., Hart, R. J. \& Whitaker, C. R. Magnesium and aromatics: mechanically-induced Grignard and McMurry reactions. Aust. J. Chem. 54, 423-425 (2001).
26. Birke, V., Schütt, C., Burmeier, H. \& Ruck, W. K. L. Defined mechanochemica reductive dechlorination of 1,3,5-trichlorobenzene at room temperature in a ball mill. Fresenius Environ. Bull. 20, 2794-2805 (2011).

27. Speight, I. R. \& Hanusa, T. P. Exploration of mechanochemical activation in solid-state fluoro-Grignard reactions. Molecules 25, 570-578 (2020).

28. Chen, H. et al. Benzene ring knitting achieved by ambient-temperature dehalogenation via mechanochemical Ullmann-type reductive coupling. $A d v$. Mater. https://doi.org/10.1002/adma.202008685 (2021).

29. Cao, Q., Howard, J. L., Wheatley, E. \& Browne, D. L. Mechanochemical activation of zinc and application to Negishi cross-coupling. Angew. Chem. Int. Ed. 57, 11339-11343 (2018).

30. Waddell, D. C., Clark, T. D. \& Mack, J. Conducting moisture sensitive reactions under mechanochemical conditions. Tetrahedron Lett. 53, $4510-4513$ (2012)

31. Seo, T., Toyoshima, N., Kubota, K. \& Ito, H. Tackling solubility issues in organic synthesis: solid-state cross-coupling of insoluble aryl halides. J. Am. Chem. Soc. 143, 6165-6175 (2021).

32. Morita, E. et al. Copper-catalyzed arylation of chlorosilanes with Grignard reagents. Bull. Chem. Soc. Jpn. 82, 1012-1014 (2009).

33. Piontek, A., Ochędzan-Siodłak, W., Bisz, E. \& Szostak, M. Nickel-catalyzed $\mathrm{C}\left(s p^{2}\right)-\mathrm{C}\left(s p^{3}\right)$ Kumada cross-coupling of aryl tosylates with alkyl Grignard reagents. Adv. Synth. Catal. 361, 2329-2336 (2019).

34. Imamoto, T., Takiyama, N. \& Nakamura, K. Cerium chloride-promoted nucleophilic addition of Grignard reagents to ketones an efficient method for the synthesis of tertiary alcohols. Tetrahedron Lett. 26, 4763-4766 (1985).

35. Imamoto, T., Takiyama, N., Nakamura, K., Hatojima, T. \& Kamiya, Y. Reactions of carbonyl compounds with Grignard reagents in the presence of cerium chloride. J. Am. Chem. Soc. 111, 4392-4398 (1989).

36. Witte, K. et al. NEXAFS spectroscopy of chlorophyll a in solution. J. Phys. Chem. B 120, 11619-11627 (2016).

37. Cooney, R. R. \& Urquhart, S. G. Chemical trends in the near-edge X-ray absorption fine structure of monosubstituted and para-bisubstituted benzenes. J. Phys. Chem. B 108, 18185-18191 (2004).

38. Pfennig, V. S., Villella, R. C., Nikodemus, J. \& Bolm, C. Mechanochemical Grignard reactions with gaseous $\mathrm{CO}_{2}$ and sodium methyl carbonate. ChemRxiv https://doi.org/10.33774/chemrxiv-2021-r0xdb (2021).

39. Wu, C., Ying, T., Yang, X., Su, W., Dushkin, A. V. \& Yu, J. Mechanochemical magnesium-mediated Minisci $\mathrm{C}-\mathrm{H}$ alkylation of pyrimidines with alkyl bromides and chlorides. Org. Lett. 23, 6423-6428 (2021).

\section{Acknowledgements}

This work was supported by the Japan Society for the Promotion of Science (JSPS) via KAKENHI grants 17 H06370 (H.I.), 18H03907 (H.I.), $20 \mathrm{H} 04795$ (K.K.), and $21 \mathrm{H} 01926$ (K.K.); the JST via CREST grant JPMJCR19R1 (H.I.); FOREST grant JPMJFR201I (K.K.); as well as by the Institute for Chemical Reaction Design and Discovery (ICReDD), which was established by the World Premier International Research Initiative (WPI), MEXT, Japan, and by MEXT (Japan) through the "Program for Leading Graduate Schools" (Hokkaido University "Ambitious Leaders Program"). R.T. would like to thank the JSPS for a scholarship (grant number 19J20824).

\section{Author contributions}

K.K. and H.I. conceived and designed the study. R.T., H.T., K.K., and H.I. co-wrote the paper. R.T., H.A., P.G., Y.G., Y.P, and T.S. performed the chemical experiments and analyzed the data. H.T. measured near-edge X-ray absorption fine structure spectra. J.J. and S.M. conducted the theoretical study. All authors discussed the results and the manuscript.

\section{Competing interests}

The authors declare no competing interests.

\section{Additional information}

Supplementary information The online version contains supplementary material available at https://doi.org/10.1038/s41467-021-26962-w.

Correspondence and requests for materials should be addressed to Koji Kubota or Hajime Ito.

Peer review information Nature Communications thanks Andrea Porcheddu and the anonymous reviewer(s) for their contribution to the peer review of this work. Peer reviewer reports are available.

Reprints and permission information is available at http://www.nature.com/reprints

Publisher's note Springer Nature remains neutral with regard to jurisdictional claims in published maps and institutional affiliations. 
(c) (i) Open Access This article is licensed under a Creative Commons Attribution 4.0 International License, which permits use, sharing, adaptation, distribution and reproduction in any medium or format, as long as you give appropriate credit to the original author(s) and the source, provide a link to the Creative Commons license, and indicate if changes were made. The images or other third party material in this article are included in the article's Creative Commons license, unless indicated otherwise in a credit line to the material. If material is not included in the article's Creative Commons license and your intended use is not permitted by statutory regulation or exceeds the permitted use, you will need to obtain permission directly from the copyright holder. To view a copy of this license, visit http://creativecommons.org/ licenses/by/4.0/.

(C) The Author(s) 2021 